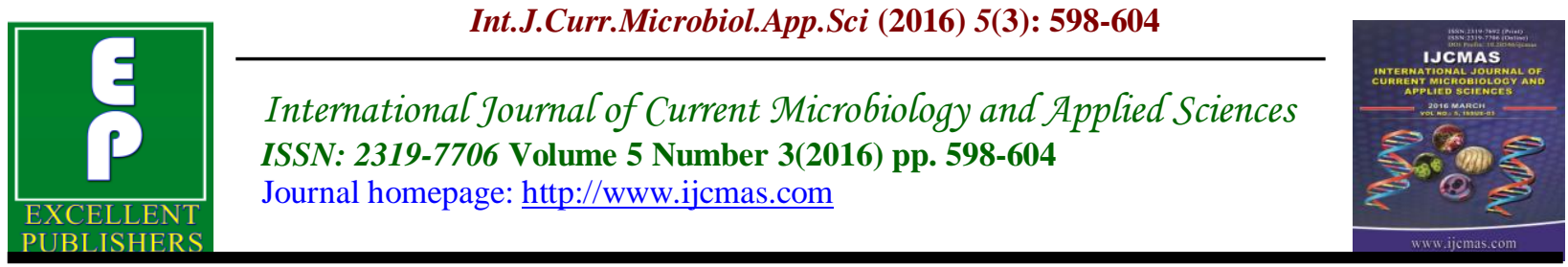

Original Research Article

http://dx.doi.org/10.20546/ijcmas.2016.503.069

\title{
Malarial Parasitic Infection in Paediatric Age Group
}

\author{
Gurjeet Singh $^{1 *}$, A.D. Urhekar ${ }^{1}$, Raksha Singh ${ }^{1}$ and Prabhakar Patro ${ }^{2}$ \\ ${ }^{1}$ Department of Microbiology, MGM Medical College and Hospital, Kamothe, Navi Mumbai- \\ 410209, Maharashtra, India \\ ${ }^{2}$ Department of Pathology, MGM Medical College and Hospital, Kamothe, Navi Mumbai- \\ 410209, Maharashtra, India \\ *Corresponding author
}

\begin{tabular}{|c|c|}
\hline & A B S T R A C T \\
\hline $\begin{array}{l}\text { Paediatric, } \\
\text { Malarial parasite, } \\
\text { Thick blood smear } \\
\text { and parasitic index }\end{array}$ & \multirow{3}{*}{$\begin{array}{l}\text { Malaria is a disease causing high morbidity and mortality of patients. } \\
\text { Plasmodium falciparum is a species causing serious fatal infections. The } \\
\text { aim of this study was to find the prevalence of malarial infection in } \\
\text { paediatric age group and to find the effect of malarial infection on blood } \\
\text { cells. Total } 500 \text { children were selected for the study who suffered with fever } \\
\text { and chills. Thick blood smear was performed using standard method. Out of } \\
500 \text { suspected cases of malaria, malarial parasites were detected in } 74 \text { blood } \\
\text { smear (14.80\%). Timely diagnosis and proper treatment may help to prevent } \\
\text { mortality of children from malaria. Thick smear is useful to screen malarial } \\
\text { parasites in large population of children and it is low cost to patient. }\end{array}$} \\
\hline Artic & \\
\hline $\begin{array}{l}\text { ed: } \\
\text { ruary } 2016 \\
\text { ble Online: }\end{array}$ & \\
\hline
\end{tabular}

\section{Introduction}

Malaria infection is caused by a protozoan parasite of the genus Plasmodium. The species known as Plasmodium falciparum is the most common cause of malaria infection. Malaria kills many young children in sub-Saharan Africa. The disease leads to numerous complications in children such as anaemia, pulmonary oedema, renal failure, hepatic dysfunction and coma. Some of the symptoms of malaria infection are fever, vomiting, sweats, chills, cough and fatigue. Although governments of most sub-Saharan African countries and international community have continued to invest in prevention and management of malaria, the disease has remained a major public health problem in Africa. ${ }^{1}$

World Health Organization reported 219 million cases of malaria with an estimated 660,000 deaths. South East Asia is the second most affected region in the world after Africa, and India has the highest (61\%) malaria burden in the region with an estimated 24 million cases per year. Plasmodium falciparum malaria continues to be a major public health threat in India, with nearly half (273 million) of the high risk population outside Africa residing in India. India contributes over one fifth $(22.6 \%)$ of 
clinical episodes of $P$. falciparum globally. About $80 \%$ of malaria cases reported in the country is confined to areas consisting of $20 \%$ of the total population, who reside in tribal, hilly, difficult and inaccessible areas. ${ }^{2}$

Malaria remains a leading cause of childhood morbidity and mortality worldwide, accounting for $7 \%$ of deaths in children younger than five years of age. In the past few years two of the largest clinical trials ever conducted in African children with severe malaria (SM) have concluded, both holding major implications for treatment guidelines. ${ }^{3}$

Malaria is an ancient scourge of humanity. Although almost eradicated from industrialized nations, malaria continues to take a heavy toll of life and health in a substantial part of the world. Almost half the world's population lives in countries where the disease is endemic, and almost every country in the world encounters imported malaria. Children are the worst affected, especially children aged 6 months to 5 years. In parts of the world where malaria is endemic, it may cause as many as $10 \%$ of all deaths in children. Malaria in children younger than age 5 years carries the worst prognosis in endemic areas. In a nonimmune population, malaria is equally deadly at all ages. Repeated attacks of malaria can lead to chronic anemia, malnutrition, and stunted growth. Acidosis, seizures, impaired consciousness, renal impairment, and preexisting chronic diseases are associated with poor outcomes in children with severe malaria. Other markers of poor outcomes are hyperparasitemia, respiratory distress, young age, severe anemia, and hypoglycemia. ${ }^{4}$

\section{Materials and Methods}

This prospective and analytical study was carried out at Microbiology and Pathology Laboratory, Mahatma Gandhi Mission
Hospital, Kalamboli, Navi Mumbai, India, over a period of one year from January 2013 to December 2013. Chi-square test, Z tests and SPSS (version 17) software was used for statistical analysis. A total of 500 samples collected from clinically suspected cases of malaria of all the paediatric age groups in both the sexes attending tertiary care hospital were included for study.

\section{Ethical Clearance}

Ethical clearance was obtained from the Institutional Ethical committee of MGM Institute of Health Sciences (Deemed University), Navi Mumbai before starting the project. Written consent was taken prior sample collection from each participant and mother / care takers under five years age

\section{Sample Collection}

The detailed history, clinical signs and symptoms were recorded in the proforma. 3$5 \mathrm{ml}$ venous blood was collected into Ethylene diamine tetra acetic acid (EDTA) tube (Becton Dickinson) under sterile precautions.

\section{Laboratory Method}

Thick smears were prepared on a clean grease free glass slide. Dehaemoglobinized and stained with Leishman's stain (Lot No. 0000168288-HiMedia Laboratories Pvt. Ltd., India) according to standard procedure and observed under 100x oil immersion objective lens using paraffin oil. The numbers of malarial parasites (Plasmodium species) in thick smear were recorded. (Fig. $1 \& 2)$.

\section{Results and Discussion}

Total 500 malaria suspected children were included in this study. Out of 74 positive samples parasitic index maximum found + 
in 41 samples i.e. (Trophozoite 41 and gametocytes 15), ++ in 24 samples (Trophozoite 24 and gametocytes 10) and
+++ in 9 samples (Trophozoite 9 and gametocytes 3).

Table.1 Showing Parasitic Index

\begin{tabular}{|c|c|c|c|}
\hline Parasite intensity & + & ++ & +++ \\
\hline Trophozoites & 41 & 24 & 9 \\
\hline Gametocytes & 15 & 10 & 3 \\
\hline
\end{tabular}

Table.2 Showing Age Wise Distribution of Malaria

\begin{tabular}{|c|c|c|}
\hline Years & No. of Patient & Percentages \\
\hline$<1$ & 3 & $4.05 \%$ \\
\hline $1-3$. & 23 & $31.08 \%$ \\
\hline $4-6$. & 18 & $24.32 \%$ \\
\hline $7-9$. & 11 & $14.86 \%$ \\
\hline $10-12$. & 19 & $25.68 \%$ \\
\hline Total & 74 & $100 \%$ \\
\hline
\end{tabular}

Fig.1 Ring Trophozoite Stage of Malarial Parasites

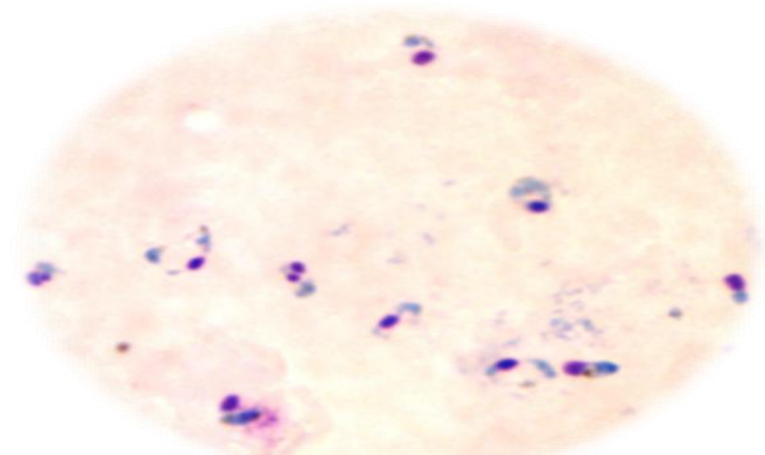

Fig.2 Gametocyte Stage of Malarial Parasites

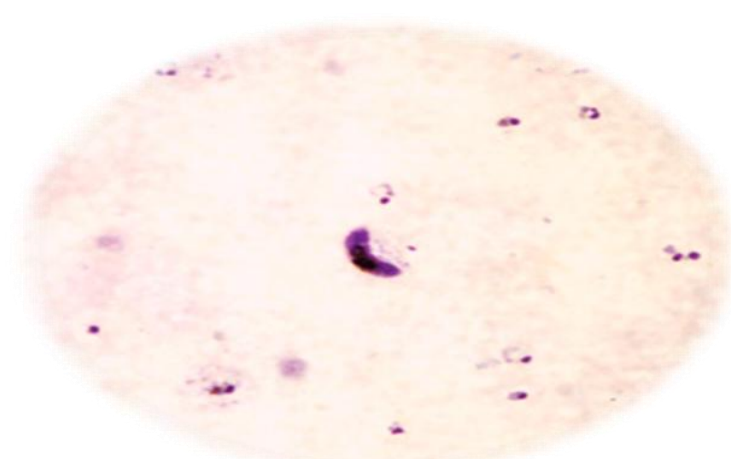


Fig.3 Prevalence of Malarial Infection in Children

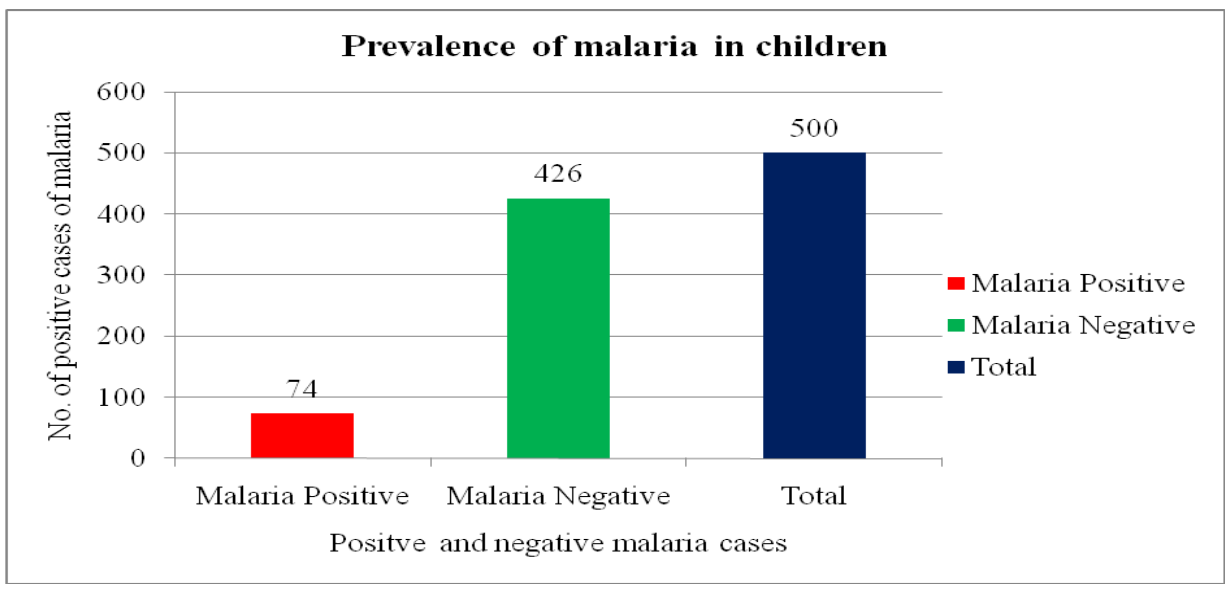

Fig.4 Parasitic Index of Malarial Parasites

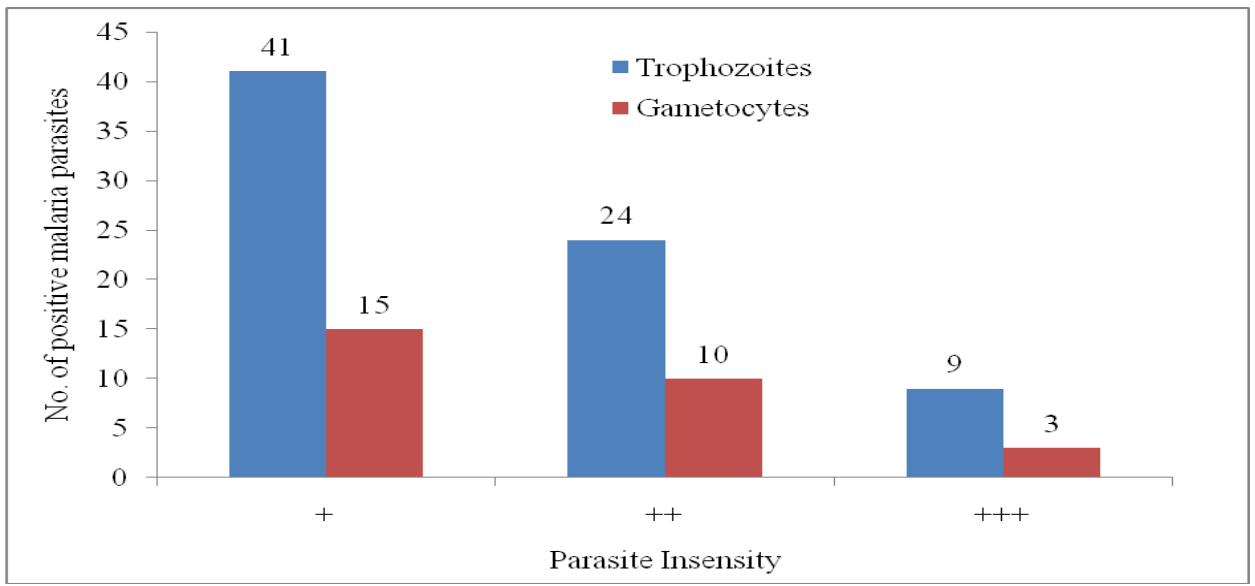

Fig.5 Age Wise Distribution of Malaria

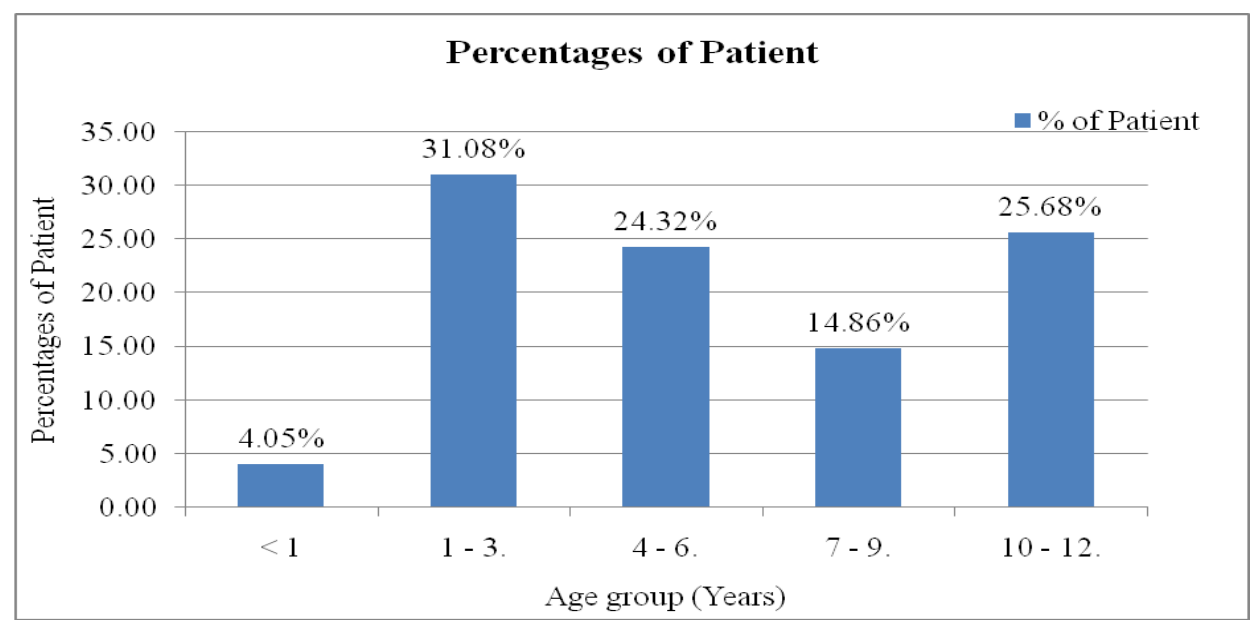


Fig.6 Sex Wise Distribution of Malaria

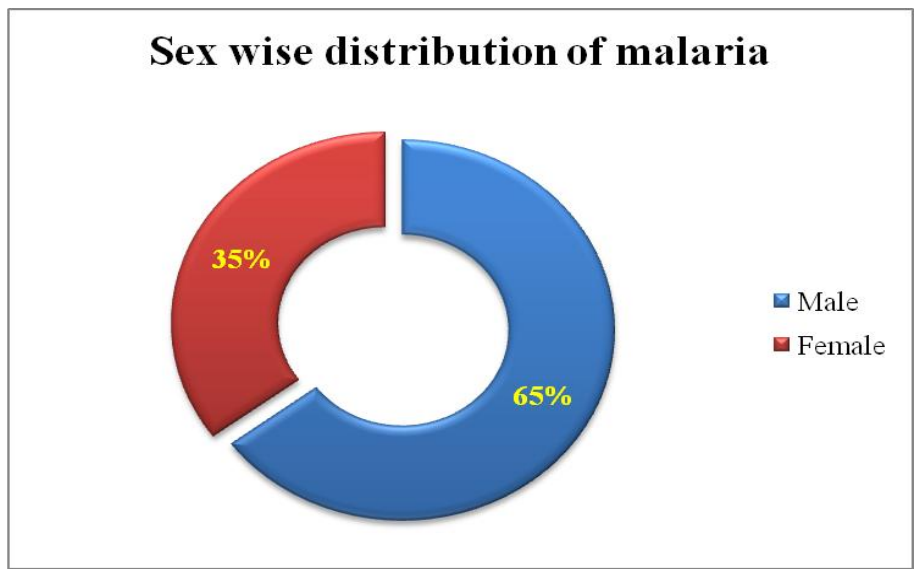

Intensity of Malaria Parasites in the Study

$+=10$ parasites per 100 thick film fields; ++ $=100$ parasites per 100 thick film fields; $+++=10$ parasites, per one thick film fields; and $++++=$ more than parasites per one thick film fields ${ }^{5,6}$.

Malaria is one of the most important causes of direct or indirect infant, child, and adult morbidity and mortality in India. $P$. vivax malaria is considered to be benign malaria with a very low case-fatality ratio; it may still cause a severe illness similar to $P$. falciparum malaria, especially in children. ${ }^{7,8}$ Studies from Asia and the Pacific region have showed that $P$. vivax malaria responsible for large number patients admitted in hospital. ${ }^{9,10-13} P$. vivax being a benign infection and causing severe form of infection reported from India, ${ }^{14}$ Indonesia, ${ }^{15,16}$ Papua New Guinea, ${ }^{17}$ and Pakistan, ${ }^{18}$ workers reported $P$. vivax causing severe disease including deaths in hospitalized patients. A study from Venezuela also showed $P$. vivax associated with increasing deaths, particularly in children. $^{19}$

In our study 74 out of 500 samples were positive for malarial infection (14.80\%).
(Fig.3) Out of 74 positive samples parasitic index were maximum found + in 41 samples i.e. (Trophozoite 41 and gametocytes 15), ++ in 24 samples (Trophozoite 24 and gametocytes 10) and +++ in 9 samples (Trophozoite 9 and gametocytes 3). (Table 1 \& Fig.4)

In our study maximum numbers of malarial infection were seen in age group 1 - 3 years (31.08\%) followed by age group 10-12 years $(25.68 \%)$ and $4-6$ years $(24.32 \%)$. (Table 2 $\&$ Fig.5) Sex wise distribution - more number of malarial parasites were seen in male 48/74 (64.86\%) than female 26/74 $(35.14 \%)$. The male to female ratio was $2: 1$. $\mathrm{P}$ value $(<0.05)$, statistically significant (Table 3 \& Fig.6).

A study reported 102/179 (56.9\%) prevalence in children. $64(62.74 \%)$ were male and 38 (37.26\%) were female. Male to female ratio $2: 1 .^{20}$ Another study reported 38/1680 (2.26\%) children tested positive for malaria on peripheral smear examination. ${ }^{21}$ Another study reported that out of 5356 children suspected cases of malaria, 5100 (95.2\%) were confirmed positive for malarial parasites by microscopic examination. Age wise 4119 (80.8\%) were age group 0-6 years, with children aged 1 to 3 years being mostly affected. ${ }^{22}$ 
In conclusion, Malaria can cause severe and fatal condition encountered in all age groups if not properly diagnosed and untreated. Thick smear is a useful to screen malarial parasites in large population of children i.e. in school, villagers, camp and it is low cost to patient.

\section{Acknowledgement}

We are thankful to the technical staff of Microbiology and Pathology laboratory of Mahatma Gandhi Mission Hospital, Kalamboli, Navi Mumbai for their support during research work.

\section{References}

1. Doreen N. Eugene-Ezebilo and Eugene E. Ezebilo. Malaria infection in children in tropical rainforest: assessments by women of Ugbowo Community in Benin City, Nigeria. Asian Pac J Trop Med 2014; 7(Suppl 1): S97-S103.

2. Qureshi I, Qureshi MA, Gudepu RK and Arlappa N. Prevalence of malaria infection among under five year tribal children residing in malaria endemic forest villages [v1; ref status: awaiting peer review, http://f1000r.es/4n4] F1000Research 2014, 3 :286 (doi: 10.12688/f1000research.5632.1)

3. Church and Maitland: Invasive bacterial co-infection in African children with Plasmodium falciparum malaria: a systematic review. BMC Medicine, 2014; 12:31. 10.1186/1741-7015-12-31.

4. http://emedicine.medscape.com/article/9 98942-overview\#a3

5. Bruce-Chwatt LJ. Essential malariology. II edn. London: William Heinemann Medical Books 1985; p. 265.

6. Olsen I, Magnussen $\mathrm{P}$, Onuma JH, Andraessen J, Frilis H. The contribution of hookworm and other parasitic infections to haemoglobin and iron status among children and adults in western Kenya. Trans $R$ Soc Trop Med Hyg 1989; 92: 643-9.

7. World Health Organization, 2008. World Malaria Report 2008. Geneva, Switzerland: World Health Organization, 9-15.

8. WHO, 2000. Severe falciparum malaria. Trans R Soc Trop Med Hyg 94 (1Suppl): S1-S90.

9. Luxemburger C, Ricci F, Nosten F, Raimond D, Bathet S, White NJ, 1997. The epidemiology of severe malaria in an area of low transmission in Thailand. Trans R Soc Trop Med Hyg 91: 256262.

10. Gopinathan VP, Subramanian AR, 1986. Vivax and falciparum malaria seen at an Indian service hospital. J Trop Med Hyg 89:51-55.

11. Maitland K, Williams TN, Peto TE, Day KP, Clegg JB, 1997. Absence of malaria-specific mortality in children in an area of hyperendemic malaria. Trans R Soc Trop Med Hyg 91: 562-566.

12. Vannaphan S, Saengnetswang $T$, Suwanakut P, Kllangbuakong A, Klinnak W, 2005 . The epidemiology of patients with severe malaria who died at the Hospital for Tropical Diseases, 1991-2004. Southeast Asian J Trop Med Public Health 36: 385-389.

13. Carrara VI, Sirilak S, Thonglairuam J, Rojanawatsirivet C, Proux S, 2006. Deployment of early diagnosis and mefloquine-artesunate treatment of falciparum malaria in Thailand: the Tak Malaria Initiative. PLoS Med 3: e183.

14. Tripathy R, Parida S, Das L, Mishra DP, Tripathy D, Das MC, Chen H, Maguire JH, Panigrahi P, 2007. Clinical manifestations and predictors of severe malaria in Indian children. Pediatrics 120:e454 - e460. 
15. Barcus MJ, Basri H, Picarima $H$, Manyakori C, Sekartuti, Elyazar I, Bangs MJ, Maguire JD, Baird JK, 2007. Demographic risk factors for severe and fatal vivax and falciparum malaria among hospital admissions in northeastern Indonesian Papua. Am J Trop Med Hyg 77: 984-991.

16. Tjitra E, Anstey NM, Sugiarto P, Warikar N, Kenangalem E, Karyana M, Lampah DA, Price RN, 2008. Multidrug-resistant Plasmodium vivax associated with severe and fatal malaria: a prospective study in Papua, Indonesia. PLoS Med 5: e128.

17. Genton B, Acremont VD, Rare L, Baea K, Reeder JC, Alpers MP, Müller I, 2008. Plasmodium vivax and mixed infections are associated with severe malaria in children: a prospective cohort study from Papua New Guinea. PLoS Med 5: e127.

18. 12. Beg MA, Sani N, Mehraj V, Jafri W, Khan MA, 2008. Comparative features and outcomes of malaria at a tertiary care hospital in Karachi, Pakistan. Int J Infect Dis 12: 37-42.

19. Rodriguez-Morales AJ, Benitez JA, Arria M, 2008. Malaria mortality in Venezuela: focus on deaths due to Plasmodium vivax in children. J Trop Pediatr 54:94-101.

20. Verma P, Shukla US, Kalraiya A. Retrospective study on clinical profile of severe malaria in children admitted in a tertiary care centre of central India. People's Journal of Scientific Research 2014; 7(1):22-26.

21. Kaushik JS, Gomber S, Dewan P. Clinical and Epidemiological Profiles of Severe Malaria in Children from Delhi, India J Health Popul Nutr 2012; 30(1):113-116.

22. Ray G, Okoguna A, Amadib AN. Epidemiology, therapeutic agents and cost of management of paediatric malaria in a Nigerian tertiary hospital $\mathbf{J}$ Vect Borne Dis, 2005; 42:87-94.

\section{How to cite this article:}

Gurjeet Singh, A.D. Urhekar, Raksha Singh and Prabhakar Patro. 2016. Malarial Parasitic Infection in Paediatric Age Group. Int.J.Curr.Microbiol.App.Sci. 5(3): 598-604. doi: http://dx.doi.org/10.20546/ijcmas.2016.503.069 